\title{
Micro-dimpled surface atelocollagen maintains primary human hepatocytes in culture and may promote their functionality compared with collagen coat culture
}

\author{
TETSURO SATO $^{1,2}$, KAYOKO SEMURA ${ }^{1}$ and ICHIRO FUJIMOTO ${ }^{1}$ \\ ${ }^{1}$ Koken Research Center, Koken Co., Ltd., Tokyo 115-0051, Japan
}

Received December 14, 2018; Accepted June 4, 2019

DOI: $10.3892 /$ ijmm.2019.4251

\begin{abstract}
Primary human hepatocytes (PHHs) are the gold standard for drug development procedures; however, maintaining functional PHHs in vitro is challenging in conventional collagen-coated cultures. In the present study, we developed a new scaffold comprising high amounts $\left(\geq 1 \mathrm{mg} / \mathrm{cm}^{2}\right)$ of atelocollagen exposed to ultraviolet radiation to induce cross-linking and improve stability. Scanning and transmission electron microscopy revealed a micro-dimpled surface (MDS) scaffold composed of randomly arranged atelocollagen fibrils. The scaffold was therefore designated as MDS atelocollagen. PHHs cultured on MDS atelocollagen were round with a compact cytoplasm and exhibited enhanced levels of albumin (ALB) secretion and cytochrome P450 (CYP) 3A4 activity. The expression of hepatocyte-related genes, such as serum proteins, drug metabolism-related CYPs, and nuclear receptors, was enhanced in cells cultured on MDS atelocollagen, but not in those cultured on conventional atelocollagen. Moreover, the abnormal gene expression of cell adhesion molecules observed in conventional atelocollagen culture was suppressed when the cells were grown on MDS atelocollagen, thereby suggesting
\end{abstract}

Correspondence to: Dr Ichiro Fujimoto, Koken Research Center, Koken Co., Ltd., 2-13-10 Ukima, Kita-ku, Tokyo 115-0051, Japan

E-mail: ichiro.fujimoto@kokenmpc.co.jp

Present address: ${ }^{2}$ Product Development Dept. 3, Koken Co. Ltd., 1-18-36 Takarada, Tsuruoka, Yamagata 997-0011, Japan

Abbreviations: AAT, a1-antitrypsin; ALB, albumin; AhR, aryl hydrocarbon receptor; CAR, constitutive androstane receptor; CYP, cytochrome $\mathrm{P} 450$; DDR, discoidin domain receptor; GSTA4, glutathione S-transferase A4; HLC, hepatocyte-like cell; HNF $4 \alpha$, hepatocyte nuclear factor $4 \alpha$; ITG, integrin; MDS, micro-dimpled surface; MRP2, multidrug resistance-associated protein 2; $\mathrm{PHH}$, primary human hepatocyte; PXR, pregnane $\mathrm{X}$ receptor; SEM, scanning electron microscopy; TO, tryptophan 2,3-dioxygenase; TEM, transmission electron microscope; UGT1A1, UDP-glucuronosyl transferase 1A1

Key words: drug development, primary human hepatocyte culture, dedifferentiation, atelocollagen, integrin a cell behavior similar to that of in vivo hepatocytes. These results suggest that MDS atelocollagen functionally preserves PHHs while conserving the simplicity of conventional $\mathrm{PHH}$ atelocollagen-coated cultures.

\section{Introduction}

Primary human hepatocytes (PHHs) represent the gold standard for drug development procedures, including the evaluation of human hepatic drug metabolism, drug clearance, drug interaction, transporter activity and hepatotoxicity (1-3). However, the use of PHHs for these purposes must be carefully considered due to the limited supply of those cells, and PHHs can be cultured for only short time periods owing to difficulties in maintaining their functionality and viability (4). Beigel et al performed genomic and proteomic analyses of cultured primary rat hepatocytes and revealed that, after $24 \mathrm{~h}$, a number of important phase I and II enzymes involved in xenobiotic metabolism (e.g., cytochrome P450s, glutathione S-transferases and sulfotransferases), as well as antioxidant enzymes (e.g., catalase, superoxide dismutase and glutathione peroxidase), were downregulated (5). They concluded that primary hepatocytes represent a suitable model for time points up to $24 \mathrm{~h}$, whereas for medium- to long-term toxicology studies, suitable cell culture systems must be urgently developed to ensure faster, cost-effective, and more sensitive toxicity predictions (5). Although induced pluripotent stem (iPS) cells or embryonic stem cell-derived hepatocyte-like cells (HLCs) are promising alternatives owing to their unlimited proliferation and differentiation capacity, HLCs have an immature phenotype and their functions may not be similar to those of PHHs $(6,7)$. In the phenotypic and functional analyses reported by Baxter et al, stem cell-derived HLCs more closely resembled fetal hepatocytes rather than adult cells; in other words, $81 \%$ of phase I enzymes in HLCs were markedly upregulated, and the expression of half of these enzymes in HLCs did not differ statistically significantly from their expression in fetal hepatocytes. In addition, HLCs secrete ALB and metabolize testosterone [cytochrome P450 (CYP) 3A] and dextrorphan (CYP2D6) in a manner similar to fetal hepatocytes (7). Therefore, PHHs are essential for in vitro studies of liver molecular mechanisms as well as drug development. Thus, improvements in $\mathrm{PHH}$ culturing are crucial.

Collagen is an extracellular matrix (ECM) protein commonly used to culture PHHs. Coating culture dishes with 
collagen type I enhances hepatocyte attachment and survival, and also promotes the maintenance of liver-specific phenotypes (2). Conventional 2D culture of hepatocytes is easily achievable and represents the most common culture strategy (3). The conventional collagen coat comprises extremely small amounts (in the order of $\mu \mathrm{g} / \mathrm{cm}^{2}$ ) of collagen $(1,8)$. PHHs cultured on conventional collagen-coated dishes rapidly dedifferentiate and lose their hepatic function within a few days $(5,9,10)$. Several reports have indicated that hepatic function can be improved by co-culture with non-parenchymal cells (11-13) or by using collagen gel sandwich configuration models, which can maintain hepatic function, polarity and viability $(8,14,15)$. However, the uppermost collagen matrix layer in the sandwich culture system prevents access to test compounds on PHHs, and co-culture adds additional complications compared with conventional culture. Therefore, without complicating culture methods, we sought to improve the conventional collagen-coated monolayer cultures, which are currently the gold standard for drug development procedures.

In atelocollagen, telopeptides are enzymatically depleted, resulting in low immunogenicity. In addition, atelocollagen has the same typical triple helix structure as native collagen, and it can form collagen fibrils under physiological conditions; therefore, it is compatible with both in vivo and in vitro applications, such as regenerative medicine $(16,17)$ and drug delivery systems $(18,19)$. We developed a new scaffold comprising higher amounts (in the order of $\mathrm{mg} / \mathrm{cm}^{2}$ ) of atelocollagen compared with conventional atelocollagen coating $\left(\mu \mathrm{g} / \mathrm{cm}^{2}\right)$ and induced cross-linking via exposure to ultraviolet (UV) radiation to improve stability.

Several thick collagen scaffolds, such as conventional collagen gel or collagen membrane vitrigel $(20,21)$, which are composed of high-density collagen fibrils, have been described previously. Takezawa et al characterized collagen vitrigel using scanning electron microscopy (SEM) and found that both conventional collagen gel and collagen vitrigel display a reticular network architecture composed of numerous collagen fibrils, as well as characteristic cross-striations every $\sim 70 \mathrm{~nm}$ for individual collagen fibrils (20). Our scaffold differs from these scaffolds in terms of the presence of a micro-dimpled surface (MDS). In the present study, we first compared a conventional atelocollagen coat with one featuring large amounts of atelocollagen scaffolds; this coat was also referred to as MDS atelocollagen, had a characteristic structure and maintained PHH functionality. Moreover, MDS atelocollagen suppressed the abnormal expression of cell adhesion molecules observed on conventional atelocollagen coats, suggesting that cells grown on MDS atelocollagen may behave similar to in vivo hepatocytes. We herein describe a novel culture model developed using MDS atelocollagen to maintain PHHs in culture using the conventional atelocollagen coat culture without a complicated culture method.

\section{Materials and methods}

Preparation of atelocollagen coats. A $5-\mathrm{mg} / \mathrm{ml}$ solution of type I atelocollagen (IPC-50; Koken) derived from bovine dermis was used for atelocollagen coating. The atelocollagen solution was added to 96 -well cell culture plates to final densities of $0.04,0.2,1$ and $2 \mathrm{mg} / \mathrm{cm}^{2}$ following air-drying for 5 days on a clean bench. The atelocollagen solution was diluted using $1 \mathrm{mM} \mathrm{HCl}$ to obtain two dilutions as follows: $0.25 \mathrm{mg} / \mathrm{ml}$ for $0.04 \mathrm{mg} / \mathrm{cm}^{2}$ and $1.25 \mathrm{mg} / \mathrm{ml}$ for $0.2 \mathrm{mg} / \mathrm{cm}^{2}$. One millimolar $\mathrm{HCl}$ was selected as the dilution buffer, as it was also used to prepare IPC-50 atelocollagen. The diluted solutions $(50 \mu \mathrm{l})$ were added to the 96 -well plates. For the 1- and $2-\mathrm{mg} / \mathrm{cm}^{2}$ atelocollagen solutions, the $5-\mathrm{mg} / \mathrm{ml}$ atelocollagen solution was directly added to $96-$ well plates without dilution (64 $\mu \mathrm{l}$ for $1 \mathrm{mg} / \mathrm{cm}^{2}$ and $128 \mu l$ for $2 \mathrm{mg} / \mathrm{cm}^{2}$ ). During air-drying, the plate lids were opened, and UV radiation was stopped to prepare a non-uniform coat and regulate UV-induced cross-linking. Furthermore, atelocollagen was cross-linked using 254-nm UV radiation at $0.5 \mathrm{~J} / \mathrm{cm}^{2}$ delivered on two separate occasions using a UV cross-linker (CL-1000; UVP). The atelocollagen-coated plates were stored at room temperature.

SEM. Atelocollagen samples were fixed with $2 \%$ glutaraldehyde, sequentially dehydrated in ethanol, and embedded in tert-butyl alcohol. The samples were then freeze-dried and sputter-coated with osmium using an osmium coater (Neoc-STB; Meiwafosis Co., Ltd.). Images were obtained using a scanning electron microscope (SU6600; Hitachi High-Technologies). The micro-roughness of the samples was assessed via ISO 25178-compliant motif analysis (bottom detection) using MountainsMap ${ }^{\circledR}$ software (Digital Surf) based on the SEM images. The method, presently called segmentation, is based on the application of a watershed algorithm associated with an algorithm for simplifying graphs that describe the relationships between individual points (Wolf pruning) (22). Details on feature parameters were described by Blateyron (23).

Transmission electron microscopy (TEM). Atelocollagen samples were fixed with $2 \%$ glutaraldehyde, sequentially dehydrated in ethanol and embedded in Epon. The samples were cut into 70-nm sections using an ultramicrotome (Leica EM UC7; Leica Microsystems) and stained with uranium acetate. Images were captured using a transmission electron microscope (JEM-1400Plus; JEOL Ltd.).

PHH cultures. One day before the cells were cultured, 96-well atelocollagen-coated plates were washed and pre-incubated with medium to ensure sufficient reconstruction of atelocollagen and a smooth cell culture. Briefly, the wells were washed twice with Dulbecco's phosphate-buffered saline (DS Pharma Biomedical), incubated with $50 \mu \mathrm{l} /$ well hepatocyte culture medium (HCM; Lonza Bioscience) supplemented with $2 \%$ fetal bovine serum (FBS), and then incubated at $37^{\circ} \mathrm{C}$ overnight. The next day, cryopreserved human hepatocytes (HUCPI; Lonza Bioscience) were cultured according to the manufacturer's instructions with minor modifications. All the series of PHHs from this supplier are produced from a single donor. PHHs, which demonstrated $87 \%$ viability using trypan blue staining, were seeded directly into pre-incubated atelocollagen-coated 96-well plates at a density of $1 \times 10^{5}$ cells $/ 100 \mu \mathrm{l} /$ well (total, $150 \mu \mathrm{l} /$ well) and incubated under a humidified atmosphere of $5 \% \mathrm{CO}_{2}$ at $37^{\circ} \mathrm{C}$. For the first $24 \mathrm{~h}, \mathrm{HCM}$ supplemented with $2 \%$ FBS was used as the culture medium; thereafter, this medium was replaced daily with HCM without FBS. 
LIVE/DEAD assay. The medium was replaced with HCM containing $2 \mu \mathrm{M}$ calcein $\mathrm{AM}, 4 \mu \mathrm{M}$ ethidium homodimer (LIVE/DEAD ${ }^{\mathrm{TM}}$ Viability/Cytotoxicity kit for mammalian cells; Thermo Fisher Scientific, Inc.), and $0.5 \mu \mathrm{g} / \mathrm{ml}$ Hoechst 33342 (Dojindo Molecular Technologies, Inc.). The cells were then incubated at $37^{\circ} \mathrm{C}$ under a humidified atmosphere of $5 \% \mathrm{CO}_{2}$ for $5 \mathrm{~min}$. Thereafter, the medium was replaced with fresh HCM. Fluorescence was imaged using an IX83 microscope (Olympus Corporation).

Human ALB ELISA. The ALB level in the culture medium was measured using ELISA kits (Bethyl Laboratories, Inc.), following the manufacturer's instructions. Briefly, the culture medium was changed 1 day prior to sampling. The conditioned medium in which PHHs were cultured for $24 \mathrm{~h}$ was then collected and centrifuged at $625 \mathrm{x}$ g for $1 \mathrm{~min}$ at $4^{\circ} \mathrm{C}$ to eliminate cell debris. The supernatant was stored at $-80^{\circ} \mathrm{C}$ until ELISA was performed. Total RNA was extracted using an RNeasy micro kit (Qiagen) on day 3 of culture according to manufacturer's instructions, and measured using a NanoDrop 2000c spectrophotometer (Thermo Fisher Scientific, Inc.).

CYP activity. CYP3A4 activity was measured using a P450-Glo ${ }^{\text {TM }}$ CYP3A4 Assay with Luciferin-IPA (Promega Corporation), following the manufacturer's instructions. Luminescence was measured in duplicates using an ARVO MX (PerkinElmer, Inc.) plate reader. CYP3A4 activity values were corrected using total RNA amount values. Total RNA was extracted using an RNeasy micro kit (Qiagen) according to the manufacturer's instructions, from wells different from those used for the CYP assay on day 3, and was measured using NanoDrop 2000c (Thermo Fisher Scientific, Inc.). For the CYP3A4 induction assay, the culture medium was replaced with HCM containing $25 \mu \mathrm{M}$ rifampicin (Sigma-Aldrich; Merck KGaA) in $0.1 \%$ dimethyl sulfoxide (DMSO) or vehicle control (0.1\% DMSO alone) on day 1. Rifampicin is the drug most commonly used to induce CYP3A enzyme activity. In addition, this induction route may be used by different medications, such as phenobarbital (24). On the following day, the medium was replaced with fresh medium containing the inducer or vehicle. After $48 \mathrm{~h}$ of treatment, CYP3A4 activity was measured as described above.

Reverse transcription-quantitative polymerase chain reaction (RT-qPCR) analysis. Total RNA was extracted using an RNeasy micro kit (Qiagen), following the manufacturer's instructions. Total RNA was reverse-transcribed using a PrimeScript ${ }^{\mathrm{TM}}$ RT reagent kit (Perfect Real Time; Takara Bio, Inc.), following the manufacturer's instructions. RT-qPCR was performed using a LightCycler 1.5 (LightCycler3 software; Roche) and SYBR ${ }^{\circledR}$ Premix Ex Taq ${ }^{\mathrm{TM}}$ (Tli RNaseH Plus; Takara Bio, Inc.). The primer sequences used are listed in Table SI. The PCR conditions were as follows: Denaturation at $95^{\circ} \mathrm{C}$ for $60 \mathrm{sec} ; 40$ cycles at $95^{\circ} \mathrm{C}$ for $5 \mathrm{sec}$ and $60^{\circ} \mathrm{C}$ for $20 \mathrm{sec}$; melting at $65^{\circ} \mathrm{C}$ for $15 \mathrm{sec}$; and cooling at $40^{\circ} \mathrm{C}$ for $30 \mathrm{sec}$. The final concentrations of the reagents used were as follows: $\mathrm{SYBR}^{\circledR}$ Premix Ex Taq (1X); forward primer $(0.2 \mu \mathrm{M})$; reverse primer $(0.2 \mu \mathrm{M})$; and cDNA ( $<100 \mathrm{ng}$ ). The threshold cycle was measured and normalized to the levels of glyceraldehyde 3-phosphate dehydrogenase. Analysis was performed using the $\Delta \Delta \mathrm{Cq}$ method (25).
Statistical analysis. Data are expressed as mean \pm standard deviation (SD). Statistical significance was assessed using one-way analysis of variance with Tukey's post hoc test or unpaired t-test. $\mathrm{P}<0.05$ was considered to indicate statistically significant differences. Data were analyzed using the Prism 7 software (GraphPad Software Inc.). This experiment was repeated three times.

\section{Results}

Characterization of MDS atelocollagen. To characterize the structure of the newly developed atelocollagen scaffold, we compared it with a conventional atelocollagen coat $\left(0.04 \mathrm{mg} / \mathrm{cm}^{2}\right)$. SEM and TEM images are shown in Fig. 1. The surface of the conventional $0.04-\mathrm{mg} / \mathrm{cm}^{2}$ atelocollagen coat displayed a fine, flat isotropic structure (Fig. 1A). The $0.2-\mathrm{mg} / \mathrm{cm}^{2}$ atelocollagen coat was similar to the conventional atelocollagen coat (Fig. 1B). By contrast, the surface of the 1and $2-\mathrm{mg} / \mathrm{cm}^{2}$ atelocollagen coats displayed rough anisotropic structures (Fig. 1C and D). The collagen fibrils were observed in the 1- and 2-mg/cm ${ }^{2}$ atelocollagen coats (Fig. 1C and D, arrows), but not in the $0.04-$ and $0.2-\mathrm{mg} / \mathrm{cm}^{2}$ atelocollagen coats. The characteristic dimpled structure with dimple diameters of $\sim 2-3 \mu \mathrm{m}$ was observed only on the surfaces of the 1- and $2-\mathrm{mg} / \mathrm{cm}^{2}$ atelocollagen coats (Fig. $1 \mathrm{C}$ and D, arrowheads).

To analyze the micro-roughness of the surface, ISO 25178-compliant motif analysis was performed using MountainsMap ${ }^{\circledR}$ analytical software (Fig. 1E-J); using an ISO 25178-compliant segmentation algorithm, this analysis detects an isolated area of the surface as a motif. The motif numbers of the $0.04-, 0.2-, 1-$ and $2-\mathrm{mg} / \mathrm{cm}^{2}$ atelocollagen coats were $6,410 \pm 312,5,607 \pm 772,2,274 \pm 295$ and $2,187 \pm 222$, respectively (Fig. 1I). The $1-$ and $2-\mathrm{mg} / \mathrm{cm}^{2}$ atelocollagen coats comprised fewer motifs compared with the conventional and $0.2-\mathrm{mg} / \mathrm{cm}^{2}$ atelocollagen coats, thereby indicating that the surface of MDS atelocollagen coat is rougher compared with that of the conventional atelocollagen coat. The average motif areas of the $0.04-, 0.2-, 1-$ and $2-\mathrm{mg} / \mathrm{cm}^{2}$ atelocollagen coats were $0.07 \pm 0.00,0.09 \pm 0.01,0.21 \pm 0.03$ and $0.22 \pm 0.02 \mu \mathrm{m}^{2}$, respectively (Fig. $1 \mathrm{~J}$ ). This indicates that the $1-$ and $2-\mathrm{mg} / \mathrm{cm}^{2}$ atelocollagen coats comprised a motif approximately thrice the size of that comprised by the conventional atelocollagen coat. As shown in Fig. 1I and J, statistically significant differences $(\mathrm{P}<0.0001)$ were observed between the low-density groups of 0.04 and $0.2 \mathrm{mg} / \mathrm{cm}^{2}$ and the high-density groups of 1 and $2 \mathrm{mg} / \mathrm{cm}^{2}$ for all combinations. As was the case for the comparison between the groups of 0.04 and $0.2 \mathrm{mg} / \mathrm{cm}^{2}$, there was no significant difference between the groups of 1 and $2 \mathrm{mg} / \mathrm{cm}^{2}$. Therefore, there may be structural differences between the low- and high-density groups.

Collagen molecules have a rod-like structure, with a length and width of 300 and $1.5 \mathrm{~nm}$, respectively (26). TEM was used to determine the arrangement of collagen molecules. In the conventional atelocollagen coat, no fibril structure or spaces were observed (Fig. 1K). By contrast, the MDS atelocollagen coat comprised randomly arranged collagen fibrils (Fig. 1L, arrows) surrounded by spaces (Fig. 1L). Consistent with the SEM image (Fig. 1D), dimpled structures were observed on the surface of the MDS atelocollagen coat (Fig. 1L, arrowheads). 

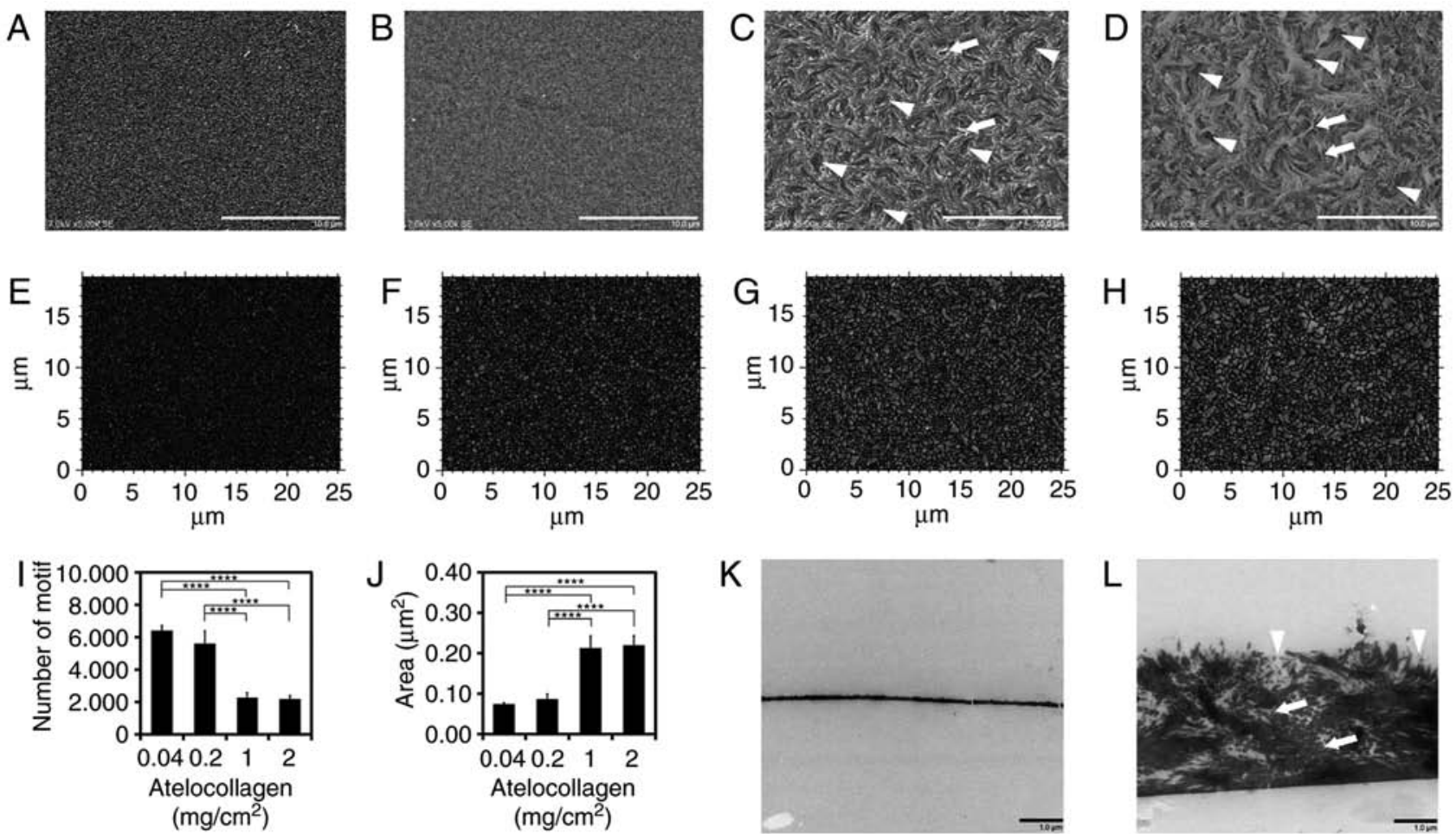

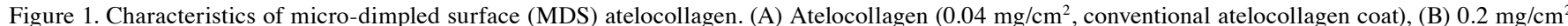
atelocollagen, (C) MDS atelocollagen $\left(1 \mathrm{mg} / \mathrm{cm}^{2}\right)$, and (D) MDS atelocollagen $\left(2 \mathrm{mg} / \mathrm{cm}^{2}\right)$ observed using scanning electron microscopy. Arrows, representative collagen fibril. Arrowheads, representative MDS. Scale bars: $10 \mu \mathrm{m}$. (E) Motif analysis of $0.04 \mathrm{mg} / \mathrm{cm}^{2} \mathrm{conventional} \mathrm{atelocollagen,} \mathrm{(F)} 0.2 \mathrm{mg} / \mathrm{cm}^{2}$, (G) $1 \mathrm{mg} / \mathrm{cm}^{2}$, and (H) $2 \mathrm{mg} / \mathrm{cm}^{2}$ atelocollagen using the Digital Surf MountainsMap ${ }^{\circledR}$ analytical software. (I) Number of motifs ( $\mathrm{n}=4$ ). (J) Average area of motif ( $\mathrm{n}=4)$. Transmission electron microscopy observation of $(\mathrm{K}) 0.04 \mathrm{mg} / \mathrm{cm}^{2}$ conventional atelocollagen and (L) MDS atelocollagen $\left(2 \mathrm{mg} / \mathrm{cm}^{2}\right)$. Arrows, representative collagen fibril. Arrowheads, representative MDS. Scale bars: $1 \mu \mathrm{m}$. All images were taken near the center of the well. (K) Two cracks observed in collagen are artifacts. Statistical analysis was performed using one-way analysis of variance and Tukey's post hoc test. The confidence level was set at ***** $\mathrm{P}<0.0001$

MDS atelocollagen alters the morphological characteristics of PHHs. To evaluate the impact of the atelocollagen content on PHH morphology and viability, PHHs were cultured on different amounts of atelocollagen and their morphology and viability were observed using LIVE/DEAD staining. LIVE/DEAD and phase contrast merged images are presented in Fig. 2. PHHs grown on the $0.04-\mathrm{mg} / \mathrm{cm}^{2}$ atelocollagen coat exhibited the typical polygonal shape on day 1 (Fig. 2A) that gradually extended on days 3 and 7 (Fig. 2B and C), indicating dedifferentiation. PHHs grown on the $0.2-\mathrm{mg} / \mathrm{cm}^{2}$ atelocollagen coat were slightly swollen on day 1 (Fig. 2D), and on days 3 and 7 the morphology was similar to that of cells grown on the $0.04-\mathrm{mg} / \mathrm{cm}^{2}$ atelocollagen coat (Fig. 2E and F). By contrast, PHHs cultured on $1-$ or $2-\mathrm{mg} / \mathrm{cm}^{2} \mathrm{MDS}$ atelocollagen coats were round with an extremely compact cytoplasm (Fig. 2G and J). Cells cultured on MDS atelocollagen were markedly smaller compared with those grown on 0.04 - or $0.2-\mathrm{mg} / \mathrm{cm}^{2}$ atelocollagen coats (Fig. $2 \mathrm{G}$ and $\mathrm{J}$ ). The round shape of the cells grown on MDS atelocollagen was maintained until day 3 (Fig. 2H and K). Motile and islet-like morphologies were observed on day 7 (Fig. 2I and L), suggesting higher cell-cell interactions compared with those observed on day 3, confirming lack of dedifferentiation (Fig. 2I and L).

As revealed by the viability of almost all cells, cell survival on day 1 was not affected by the atelocollagen scaffolds (Fig. 2A, D, G and J). Cell viability declined over time on all scaffolds, with cell death rates increasing with increasing atelocollagen content. By contrast, for lower commercial-grade PHHs (HUCPM; Lonza Bioscience), only few viable cells were observed on the conventional $0.04-\mathrm{mg} / \mathrm{cm}^{2}$ atelocollagen coat on day 7, whereas more cells remained on MDS atelocollagen (data not shown). On MDS atelocollagen, a large number of dead cells was temporally observed on day 3 (Fig. $2 \mathrm{H}$ and $\mathrm{K}$, red color); however, the dead cells were removed by medium replacement, and most cells were viable on day 7 (Fig. 2I and L). During the culture period, green fluorescence intensity (calcein AM) was low on the 0.04 - and $0.2-\mathrm{mg} / \mathrm{cm}^{2}$ atelocollagen coats and high on the $1-$ and $2-\mathrm{mg} / \mathrm{cm}^{2} \mathrm{MDS}$ atelocollagen coats, indicating that the latter exhibited enhanced esterase activity.

MDS atelocollagen enhances ALB secretion and CYP activity. ALB secretion and CYP activity are generally used as markers of hepatocyte function. Therefore, to investigate the impact of atelocollagen content on $\mathrm{PHH}$ function, ALB secretion and CYP3A4 activity were compared among cells grown on various matrices. ALB secretion into the medium increased with increasing atelocollagen content (Fig. 3A). The cells grown on the $1-\mathrm{mg} / \mathrm{cm}^{2}$ atelocollagen coat demonstrated 4.7-fold higher 24-h ALB secretion compared with those grown on the $0.04-\mathrm{mg} / \mathrm{cm}^{2}$ atelocollagen coat $(7.0 \pm 1.1$ vs. $1.5 \pm 0.3 \mu \mathrm{g} / \mu \mathrm{g}$ RNA, respectively; Fig. 3A). Furthermore, the CYP3A4 activity was observed to increase with increasing atelocollagen content (Fig. 3B). The CYP3A4 activity in 

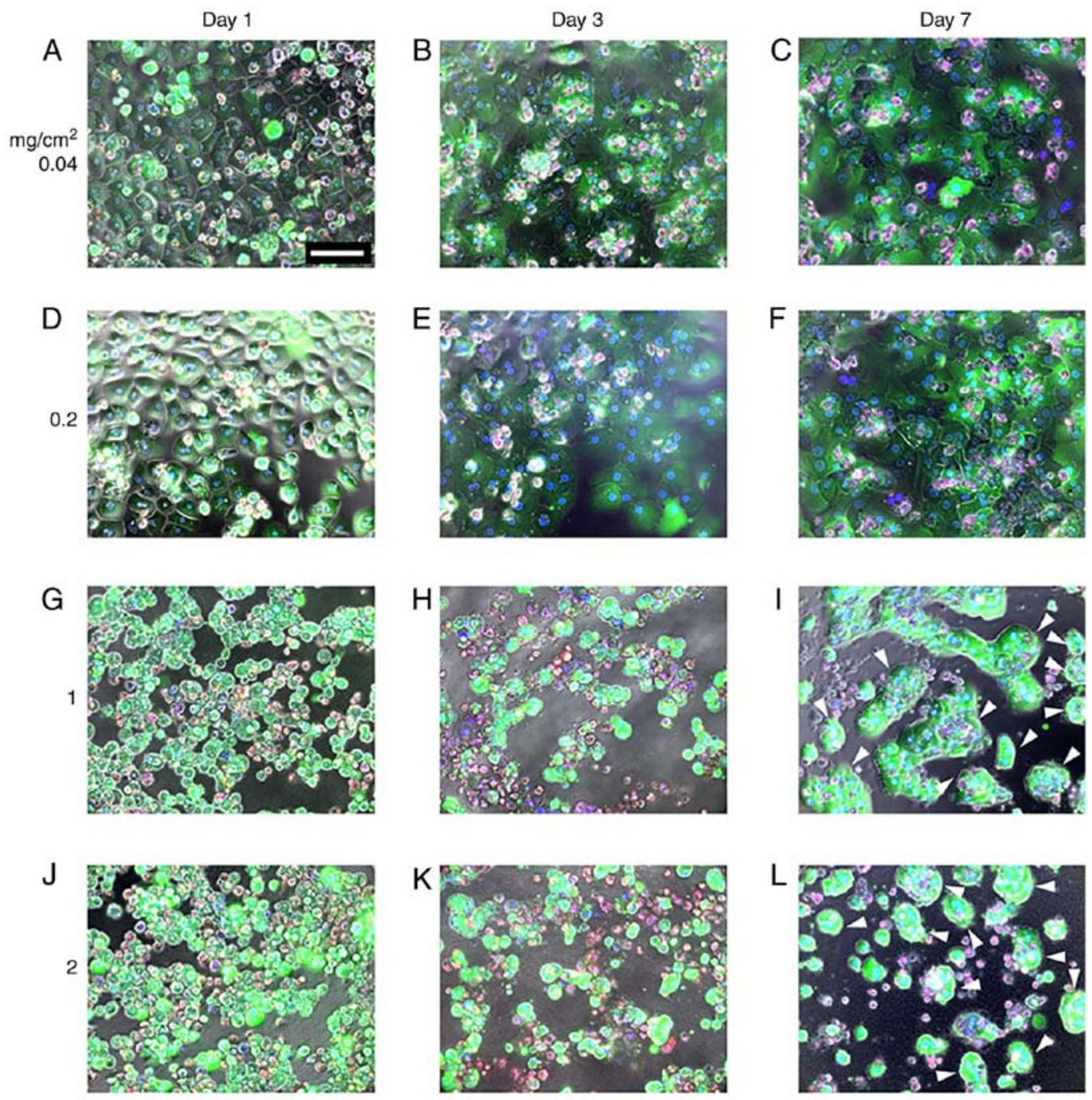

Figure 2. Collagen content affects the morphology of primary human hepatocytes (PHHs). LIVE/DEAD staining images of PHHs grown on different amounts of collagen. (A-C) Conventional $0.04 \mathrm{mg} / \mathrm{cm}^{2}$ atelocollagen. (D-F) $0.2 \mathrm{mg} / \mathrm{cm}^{2}$ atelocollagen. (G-I) $1 \mathrm{mg} / \mathrm{cm}^{2}$ atelocollagen. (J-L) $2 \mathrm{mg} / \mathrm{cm}^{2}$ atelocollagen. Islet-like morphology consisting of multiple cells indicate cell-cell interactions (arrowhead). Live cells were stained with calcein AM (green), whereas dead cells were stained with ethidium homodimer (red). Nuclei were stained with Hoechst (blue). Scale bar: $100 \mu \mathrm{m}$.

PHHs grown on the $1-\mathrm{mg} / \mathrm{cm}^{2}$ atelocollagen coat was 3.4-fold higher compared with that in cells grown on the conventional $0.04-\mathrm{mg} / \mathrm{cm}^{2}$ atelocollagen coat (Fig. 3B). CYP3A4 induction was analyzed using rifampicin; CYP3A4 activity increased by $11.8 \pm 2.9$-fold in the presence of rifampicin relative to the effects of DMSO (mean $\pm \mathrm{SD}$ ) in the cells grown on the conventional $0.04-\mathrm{mg} / \mathrm{cm}^{2}$ atelocollagen coat (Fig. 3C). By contrast, the CYP3A4 activity increased by $21.8 \pm 1.9$-fold in the cells grown on the $2-\mathrm{mg} / \mathrm{cm}^{2}$ atelocollagen coat. These results indicate that MDS atelocollagen promotes protein production and drug metabolism.

To further investigate the effect of atelocollagen levels on PHH function, we analyzed the expression of 15 hepatocyte-related genes using RT-qPCR. The expression of ALB, $\alpha 1$-antitrypsin (AAT) and tryptophan 2,3-dioxygenase (TO) significantly increased in the cells grown on the 2-mg/ $/ \mathrm{cm}^{2}$ MDS atelocollagen coat compared with those grown on the $0.04-\mathrm{mg} / \mathrm{cm}^{2}$ atelocollagen coat $(2.1 \pm 0.2-$, $1.5 \pm 0.1-$ and 3.6 \pm 0.3 -fold, respectively, Fig. 4A). CYP expression (1A2, 2C9, 2C19 and 2D6) also significantly increased in the cells grown on the MDS atelocollagen coat (3.0 $\pm 0.2-$,
2.0 $\pm 0.2-, 1.7 \pm 0.1$ - and 3.0 \pm 0.1 -fold, respectively; Fig. 4B). By contrast, the expressions of CYP3A4 (Fig. 4B), the phase II conjugation enzymes glutathione S-transferase A4 (GSTA4) and UDP-glucuronosyl transferase 1A1 (UGT1A1) (Fig. 4C), and the phase III transporter multidrug resistance-associated protein 2 (MRP2) (Fig. 4D) were not affected by MDS atelocollagen. Expression of the nuclear receptor aryl hydrocarbon receptor (AhR) significantly decreased in the cells grown on the MDS atelocollagen coat; by contrast, the expression of the nuclear receptors constitutive androstane receptor (CAR) and pregnane $\mathrm{X}$ receptor (PXR) significantly increased depending on the atelocollagen levels (Fig. 4E). Although not statistically significant, an increasing trend was observed for hepatocyte nuclear factor $4 \alpha$ (HNF4 $\alpha$ ) expression based on the atelocollagen levels (Fig. 4E). These results indicate that MDS atelocollagen specifically enhances hepatocyte-related protein production and CYP activity.

MDS atelocollagen is associated with the maintenance of hepatocyte-related gene expression. As PHHs immediately lose function during culturing, the maintenance of hepatic 
A

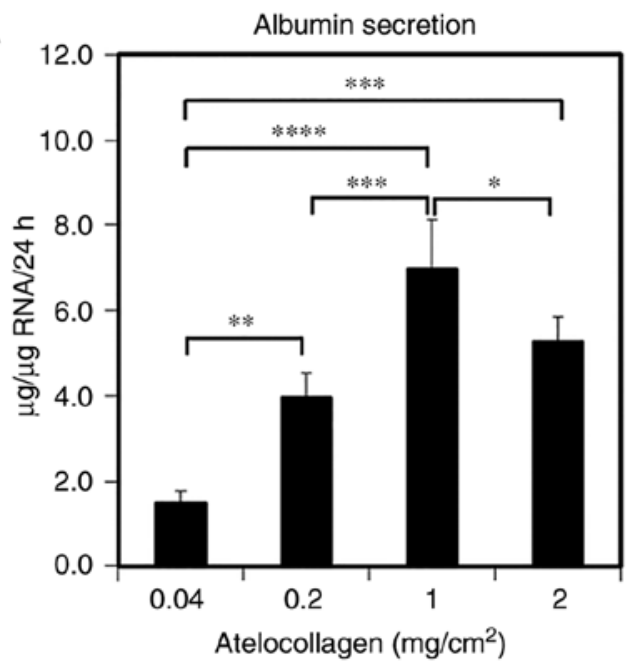

B

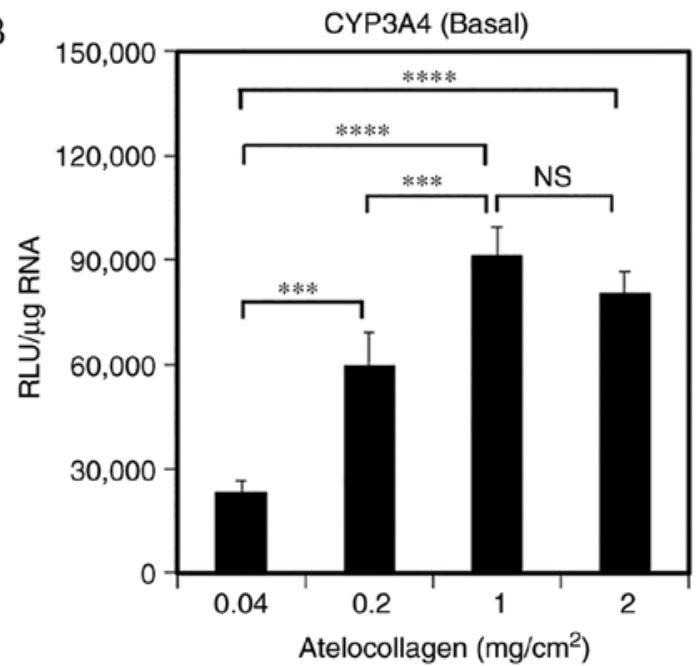

C

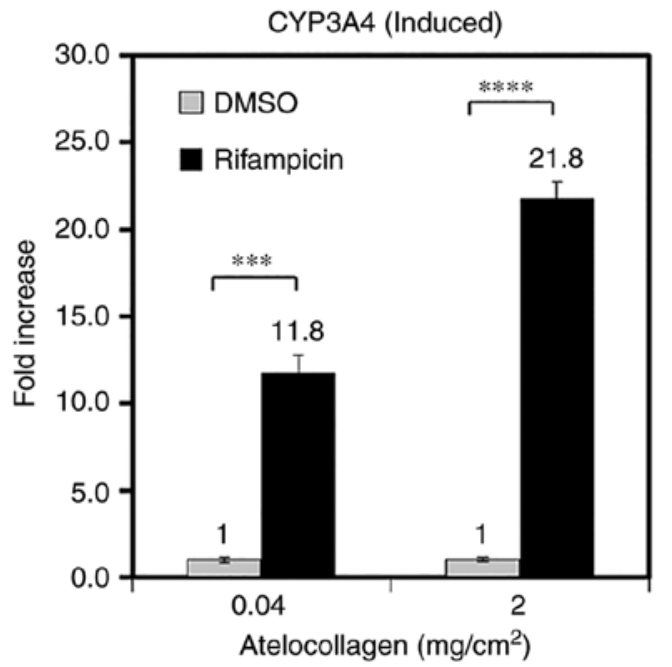

Figure 3. Atelocollagen enhances primary human hepatocyte function. (A) Albumin secretion was evaluated using ELISA on day 3 of culture (n=4). (B) Basal cytochrome P450 3A4 (CYP3A4) activity was evaluated using P450-Glo ${ }^{\mathrm{TM}}$ CYP3A4 Assay with Luciferin-IPA on day 3 of culture (n=4). (C) CYP3A4 activity induced by rifampicin $(25 \mu \mathrm{M}, 48 \mathrm{~h}, \mathrm{n}=4)$. For $(\mathrm{A})$ and (B) statistical analysis was performed using one-way analysis of variance followed by Tukey's post hoc test. ${ }^{*} \mathrm{P}<0.05,{ }^{* *} \mathrm{P}<0.01,{ }^{* * *} \mathrm{P}<0.001,{ }^{* * * *} \mathrm{P}<0.0001, \mathrm{NS}$, not significant. For $(\mathrm{C})$ statistical analysis was performed using t-test. ${ }^{* * * *} \mathrm{P}<0.001,{ }^{* * * * *} \mathrm{P}<0.0001$.

function was investigated in cells grown on various scaffolds (Fig. 5). ALB gene expression was decreased by $6.4 \pm 0.4 \%$ of the initial level on day 7 in the cells cultured on the conventional atelocollagen coat. By contrast, its expression level was maintained at $17.4 \pm 1.5 \%$ of the control level in the cells cultured on the MDS atelocollagen coat (Fig. 5A). AAT and TO gene expressions were elevated on day 7 in the cells grown

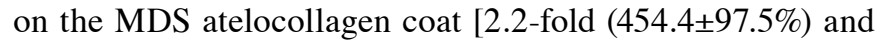
1.7-fold (20.7 $\pm 2.6 \%)$, respectively, Fig. 5A]. The expression of CYP1A2, CYP2C9, CYP2C19 and CYP2D6 in the cells grown on the MDS atelocollagen coat was elevated compared with that in the cells grown using conventional culture [3.3-fold

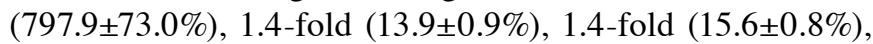
and 6.3 -fold $(9.6 \pm 0.5 \%)$, respectively; Fig. $5 \mathrm{~B}]$. These results indicate that MDS atelocollagen can maintain hepatic function more effectively compared with conventional culture.

Furthermore, the expression levels of CYP3A4 (Fig. 5B), phase II enzymes (GSTA4 and UGT1A1) and MRP2 were not increased by MDS atelocollagen (Fig. 5C and D). In addition, AhR expression was lower in the cells grown on the MDS atelocollagen coat compared with those cultured on conventional atelocollagen; moreover, the AhR expression level of these cells was similar to that in freshly thawed cryopreserved PHHs (Fig. 5E). In addition, the expression levels of CAR, PXR and HNF4 $\alpha$ genes in the cells grown on the MDS atelocollagen coat were significantly higher on day 7 compared with those in cells grown on conventional atelocollagen [6.6-fold $(6.1 \pm 0.8 \%), 1.5$-fold $(42.1 \pm 5.7 \%)$, and 1.4 -fold $(57.0 \pm 2.9 \%)$, respectively; Fig. $5 \mathrm{E}]$.

MDS atelocollagen maintains integrin (ITG) gene expression. ITGs are transmembrane cell adhesion proteins that link the cellular cytoskeleton and ECM. Hepatocytes reportedly interact with collagen via ITG $\alpha 1$ and $\beta 1$ (27). The discoidin domain receptor (DDR) is a known collagen receptor. Therefore, to investigate the cell-ECM interaction, we analyzed ITG and DDR expression using RT-qPCR. Consistently with previous findings, the expression level was low or undetectable for all genes, excluding ITG $\alpha 1$, prior to culturing on the scaffolds [before culture (BC); Fig. 6]. Compared with BC, the conventional $0.04-\mathrm{mg} / \mathrm{cm}^{2}$ atelocollagen coat induced an abnormal increase in the expression of the ITG $\alpha 2, \alpha 3, \alpha 5, \alpha 6$, 

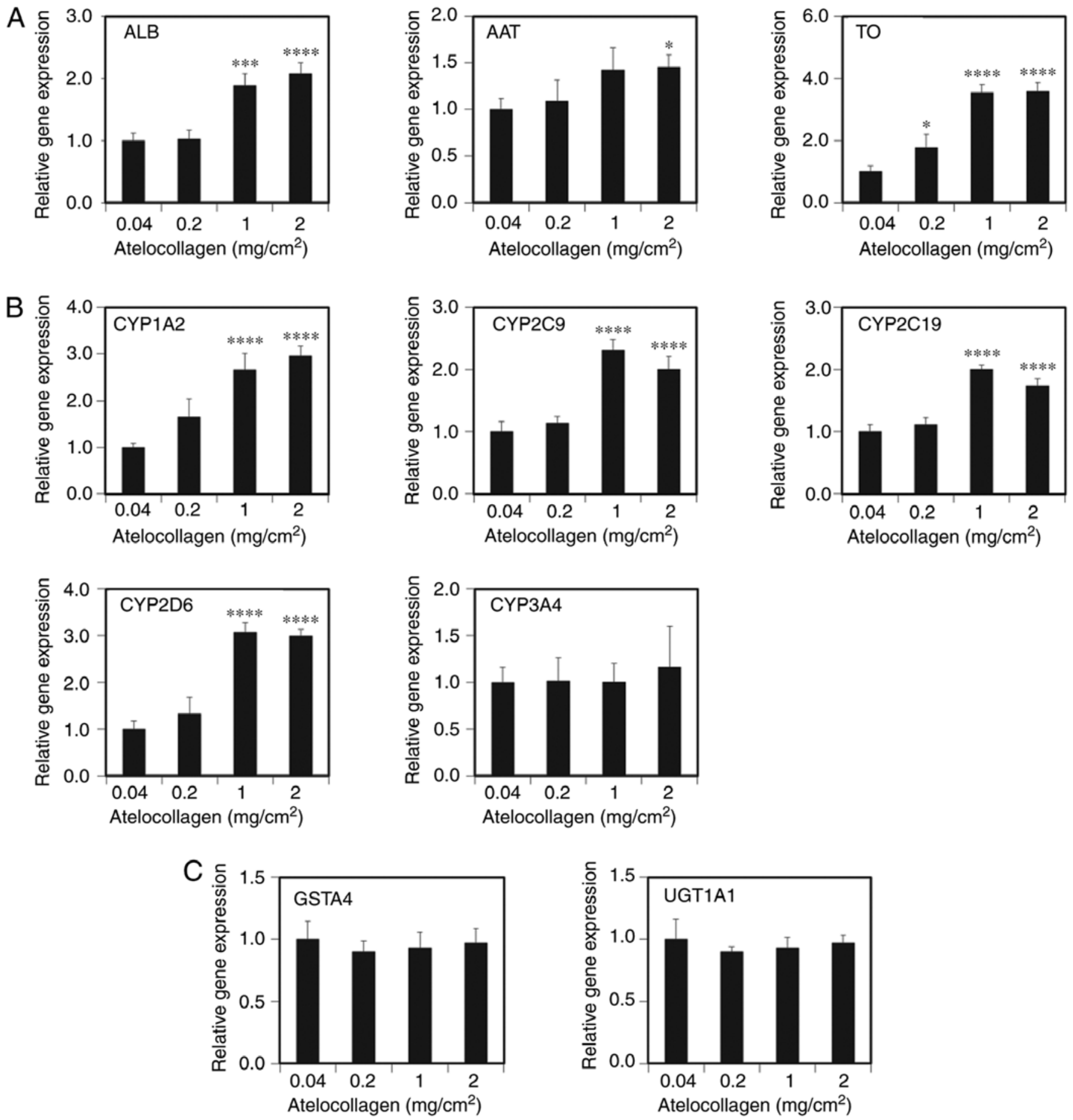

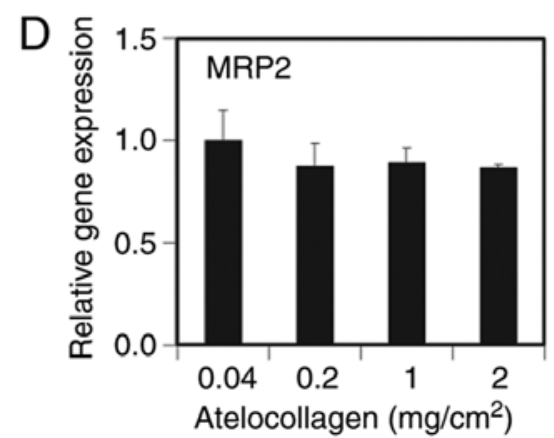

Figure 4. Hepatic gene expression based on atelocollagen content. RT-qPCR analysis on day 3 of culture. (A) Hepatocyte-related proteins. (B) Cytochrome P450s. (C) Phase II enzymes. (D) Phase III transporter. Statistical analysis was performed using one-way analysis of variance followed by Tukey's post hoc test. The post hoc test was used for comparison with $0.04 \mathrm{mg} / \mathrm{cm}^{2} .{ }^{*} \mathrm{P}<0.05,{ }^{* * *} \mathrm{P}<0.001,{ }^{* * * * *} \mathrm{P}<0.0001$. 

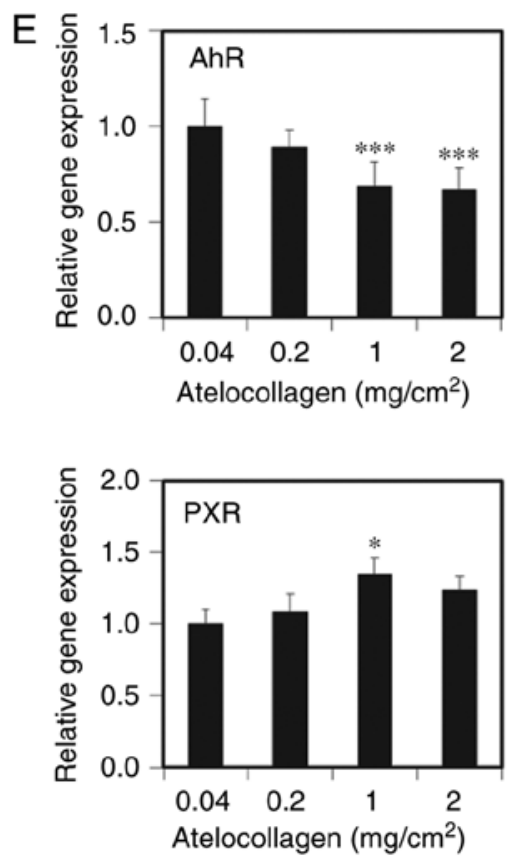
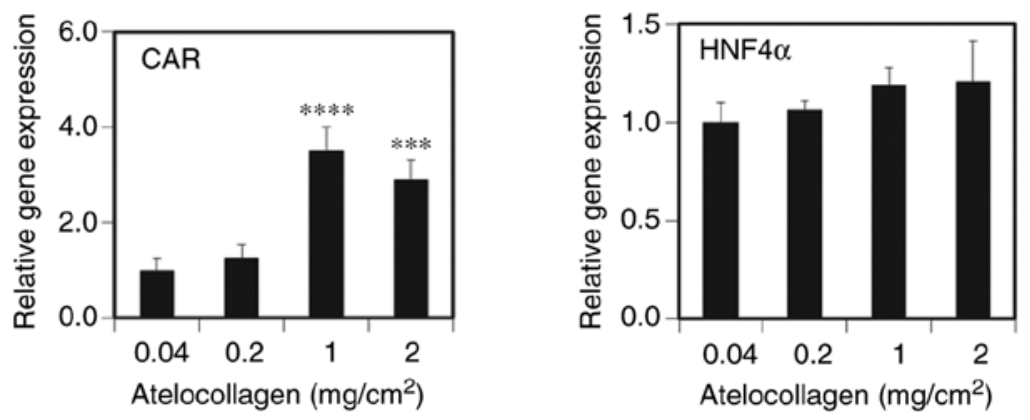

Figure 4. Continued. Hepatic gene expression based on atelocollagen content. RT-qPCR analysis on day 3 of culture. (E) Nuclear receptors. The data are presented as relative gene expression normalized to that in cells grown on conventional $0.04 \mathrm{mg} / \mathrm{cm}^{2}$ atelocollagen $\left(\mathrm{n}=4 ; 1 \mathrm{mg} / \mathrm{cm}^{2} \mathrm{of} \mathrm{HNF} 4 \alpha\right.$ is considered as $n=3$ due to the lack of cDNA). Statistical analysis was performed using one-way analysis of variance followed by Tukey's post hoc test. The post hoc test was used for comparison with $0.04 \mathrm{mg} / \mathrm{cm}^{2}$. ${ }^{*} \mathrm{P}<0.05,{ }^{* * *} \mathrm{P}<0.001,{ }^{* * * *} \mathrm{P}<0.0001$. RT-qPCR, reverse transcription-quantitative polymerase chain reaction; ALB, albumin; AAT, $\alpha 1$-antitrypsin; TO, tryptophan 2,3-dioxygenase; CYP, cytochrome P450; GSTA4, glutathione S-transferase A4; UGT1A1, UDP-glucuronosyl transferase 1A1; MRP2, multidrug resistance-associated protein 2; AhR, aryl hydrocarbon receptor; CAR, constitutive androstane receptor; HNF4 $\alpha$, hepatocyte nuclear factor $4 \alpha$; PXR, pregnane $\mathrm{X}$ receptor.

$\alpha \mathrm{V}, \beta 1$ and $\beta 3$, as well as DDR1, after 3 days of culture (Fig. 6). By contrast, low gene expression was maintained in the cells grown on the MDS atelocollagen coat (Fig. 6). Although DDR1 expression did not differ significantly between the scaffolds, its levels tended to be lower in the cells grown on the MDS atelocollagen coat compared with those grown on the conventional atelocollagen coat.

\section{Discussion}

The present study compared the morphology and function of PHHs during culturing on different concentrations of atelocollagen. Culturing cells in a three-dimensional environment is beneficial for the maintenance of hepatocyte dedifferentiation (28). In some cases, hepatic morphology and functionality are preserved for up to 4 weeks in culture. However, to use these methods, we have to resolve some of the major obstacles encountered in drug toxicity screening, such as the need for expensive equipment, large cell numbers and low throughput. In the present study, some improvements were achieved compared with monolayer cultures of primary hepatocytes on a collagen-coated dish, delaying by a few days the rapid loss of morphology and liver-specific functions, such as activities of drug-metabolizing enzymes and transporters. To the best of our knowledge, this is the first report presenting the observations of cross-sections of thin atelocollagen coats using TEM. Conventional $0.04-\mathrm{mg} / \mathrm{cm}^{2}$ atelocollagen comprised a fine, flat isotropic surface (Fig. 1A), and no collagen fibrils were observed in its cross-section images (Fig. 1K). By contrast, a 50-fold higher amount of atelocollagen $\left(2 \mathrm{mg} / \mathrm{cm}^{2}\right)$ exhibited a characteristic MDS structure (Fig. 1D). This MDS structure was also observed in $1-\mathrm{mg} / \mathrm{cm}^{2}$ atelocollagen, but not in $0.2-\mathrm{mg} / \mathrm{cm}^{2}$ atelocollagen. Therefore, $0.2-$ and $1-\mathrm{mg} / \mathrm{cm}^{2}$ atelocollagen coats are significantly different, as revealed by one-way analysis of variance (ANOVA); this was also confirmed via the findings of motif analysis (Fig. 1E-J) and cell culture experiments. The MDS atelocollagen surface structure largely affects cell behavior. Using ANOVA, we reanalyzed the data sets shown in Fig. 4; the results revealed significant differences between 0.2 and $1 \mathrm{mg} / \mathrm{cm}^{2}$ in terms of the expression of numerous genes, such as ALB, TO, CYP1A2, CYP2C9, CYP2C19, CYP2D6, AhR and CAR. Equivalent data for the genes ITG $\alpha 2$, ITG $\alpha 3$, ITG $\alpha 5$, ITG $\alpha$ V, ITG $\beta 1$ and ITG $\beta 3$ are shown in Fig. 6. In those cases, there were no statistically significant differences between 1 and $2 \mathrm{mg} / \mathrm{cm}^{2}$. These findings are strongly correlated with the data from the structural SEM analysis presented in Fig. 1. This suggests that the expression of hepatocyte-related genes is strongly affected by the structure of the cell culture surface. Due to its characteristic collagen structure, MDS atelocollagen is noticeably different from collagen gel and vitrigel $(20,21)$, which are composed of homogeneous collagen fibrils. Therefore, MDS atelocollagen is a novel collagen scaffold featuring fibrous collagen and a characteristic MDS.

The structural differences of the MDS atelocollagen coat affected the morphology and function of PHHs. Our observations corroborated a previous study that reported that mouse primary hepatocytes cultured on soft matrix were round and small, and that their function improved compared with cells grown on a stiff matrix (29). In fact, PHHs grown on stiff $2-\mathrm{mg} / \mathrm{cm}^{2}$ atelocollagen treated with $\mathrm{UV}$ radiation 

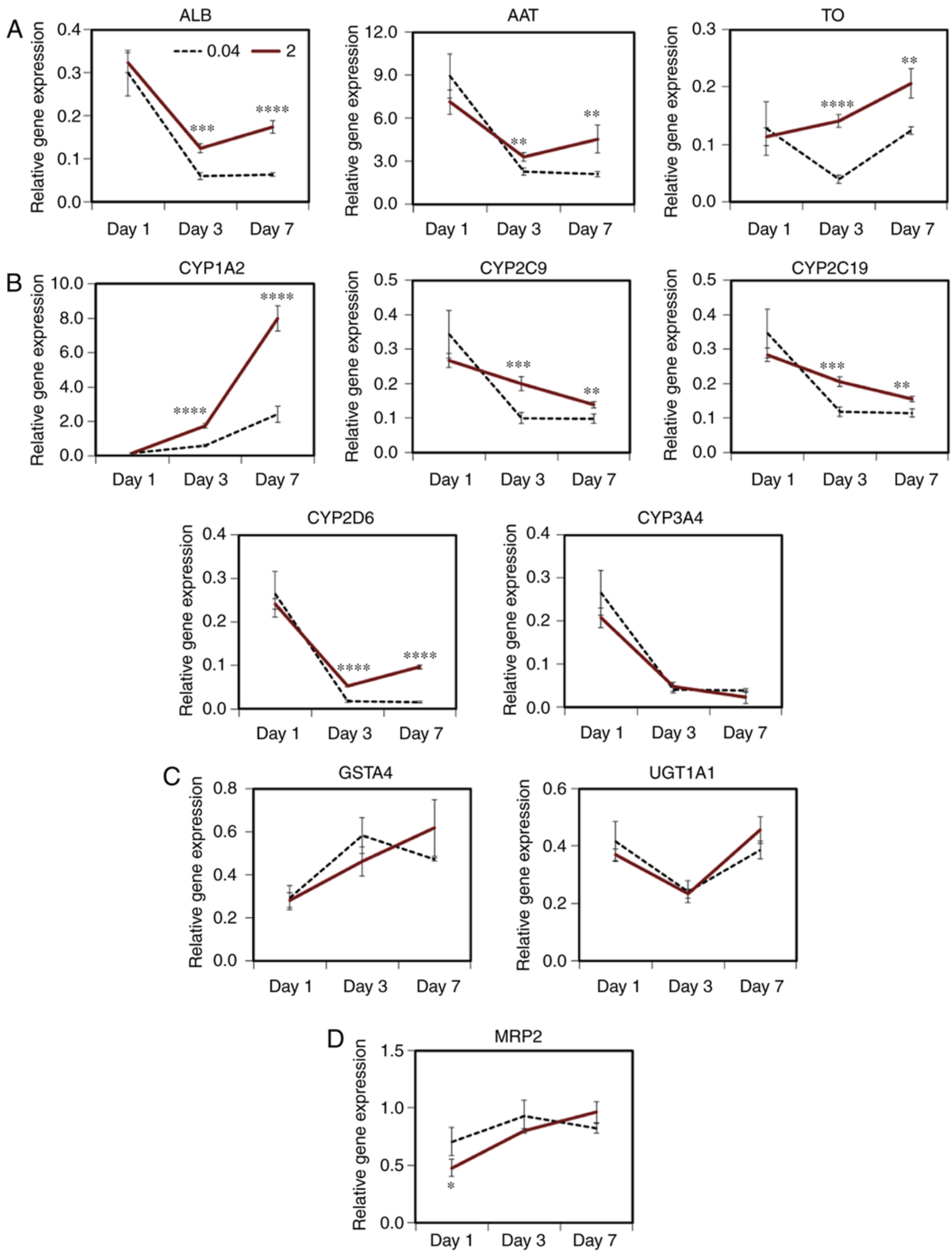

Figure 5. Maintenance of hepatic function in cells grown on micro-dimpled surface (MDS) atelocollagen. RT-qPCR analysis of gene expression in primary human hepatocytes (PHHs) cultured on conventional $0.04 \mathrm{mg} / \mathrm{cm}^{2}$ atelocollagen (----) or $2 \mathrm{mg} / \mathrm{cm}^{2}$ MDS atelocollagen (-). (A) Hepatocyte-related genes. (B) Cytochrome P450s. (C) Phase II enzymes. (D) Phase III transporter. $\mathrm{n}=4$. Statistical analysis was performed between the two groups using t-test. "P<0.05, ${ }^{* *} \mathrm{P}<0.01,{ }^{* * * *} \mathrm{P}<0.001,{ }^{* * * * *} \mathrm{P}<0.0001$. 
E
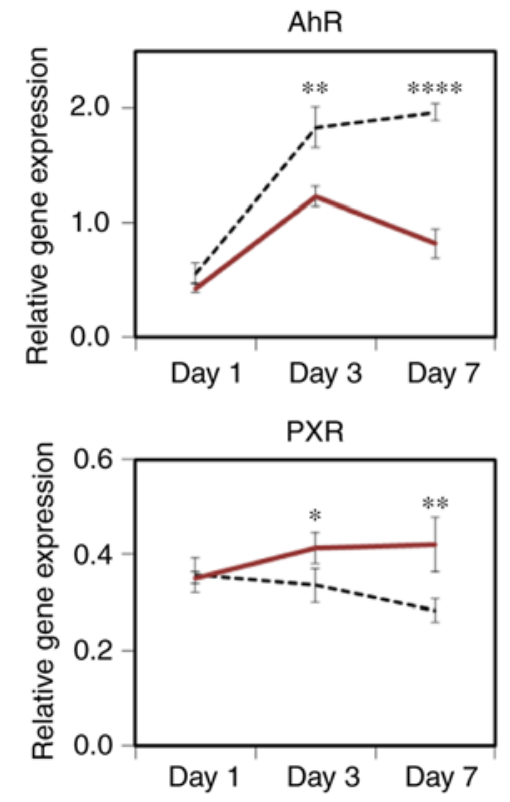
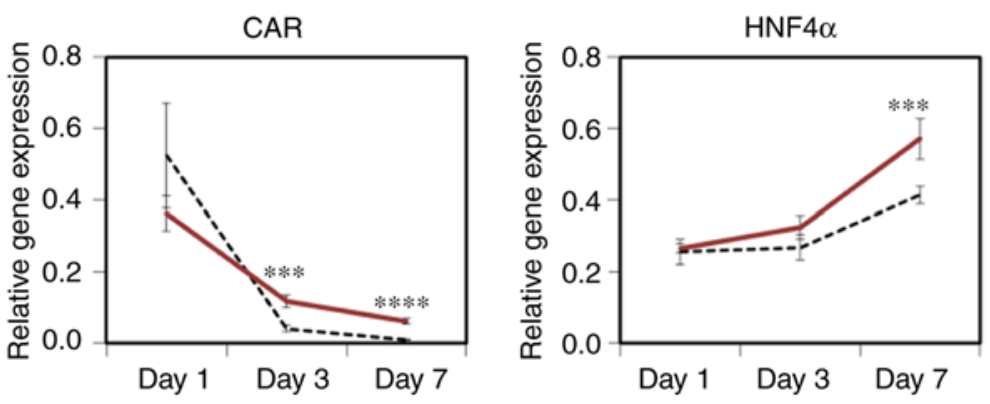

Figure 5. Continued. Maintenance of hepatic function in cells grown on micro-dimpled surface (MDS) atelocollagen. RT-qPCR analysis of gene expression in primary human hepatocytes (PHHs) cultured on conventional $0.04 \mathrm{mg} / \mathrm{cm}^{2}$ atelocollagen (----) or $2 \mathrm{mg} / \mathrm{cm}^{2} \mathrm{MDS}$ atelocollagen ( - ). (E) Nuclear receptors. The data are presented as the relative gene expression normalized to that in freshly thawed cryopreserved PHHs. $\mathrm{n}=4$. Statistical analysis was performed between the two groups using t-test. ${ }^{*} \mathrm{P}<0.05,{ }^{* *} \mathrm{P}<0.01,{ }^{* * *} \mathrm{P}<0.001,{ }^{* * * *} \mathrm{P}<0.0001$. RT-qPCR, reverse transcription-quantitative polymerase chain reaction; ALB, albumin; AAT, $\alpha 1$-antitrypsin; TO, tryptophan 2,3-dioxygenase; CYP, cytochrome P450; GSTA4, glutathione S-transferase A4; UGT1A1, UDP-glucuronosyl transferase 1A1; MRP2, multidrug resistance-associated protein 2; AhR, aryl hydrocarbon receptor; CAR, constitutive androstane receptor; HNF4 $\alpha$, hepatocyte nuclear factor $4 \alpha$; PXR, pregnane X receptor.

10 -fold higher $\left(10 \mathrm{~J} / \mathrm{cm}^{2}\right)$ compared with that used in this study exhibited an elongated shape and decreased function, similar to cells cultured on conventional $0.04-\mathrm{mg} / \mathrm{cm}^{2}$ atelocollagen (Fig. S1). These findings suggest that the rigidity of MDS atelocollagen affects hepatic cell function and morphology. The small, round shape of PHHs is attributed to the density of MDS atelocollagen. MDS atelocollagen may contain abundant cell-binding ligands, such as the ITG-recognition sequence glycine-phenylalanine-hydroxyproline-glycine-glutamate-arginine (GFOGER) or the RGD sequence. Therefore, the cells can easily attach to atelocollagen without elongation. Taken together, our findings indicate that the structure and rigidity of atelocollagen may affect the morphology and function of PHHs.

The functional characteristics of PHHs are more enhanced on MDS atelocollagen compared with conventional atelocollagen. The function of CYP3A4 was greatly increased on 1- and 2-mg/cm ${ }^{2}$ atelocollagen compared with that on lower atelocollagen concentrations; however, gene expression remained unchanged (Figs. 3B and 4B). This indicates that 1and $2-\mathrm{mg} / \mathrm{cm}^{2}$ atelocollagen may enhance CYP3A4 activity at the protein level. CYP3A4 is the CYP most highly implicated in drug metabolism; therefore, the MDS atelocollagen culture model can improve the sensitivity of drug metabolism assessments and the risk of drug-induced liver injury evaluations; this is supported by the finding that CYP3A4 induction by rifampicin increased on 1- and $2-\mathrm{mg} / \mathrm{cm}^{2}$ atelocollagen (Fig. 3C), suggesting that CYP3A4 induction is closely associated with the atelocollagen content. CYP1A2, CYP2C9, CYP2D6, CYP2C19 and CYP3A4 collectively metabolize 90\% of the currently marketed drugs; furthermore, their gene expressions are better preserved in cells grown on MDS atelocollagen compared with conventional atelocollagen. Therefore, MDS atelocollagen may contribute to several research fields, including pharmacology, toxicology, tissue engineering and clinical hepatocyte transplantation.

Intracellular focal adhesion kinase (FAK) and its downstream signaling are activated by cell attachment to collagen via ITG. FAK is activated via Src in mouse primary hepatocytes cultured on stiff and dry collagen, thereby leading to the activation of ERK and Akt signaling. Activation of the Ras/Raf/ERK pathway causes dedifferentiation and epithelial-to-mesenchymal transition, whereas activation of the phosphoinositide-3-kinase/Akt pathway causes resistance to apoptosis (30). FAK activation was suppressed in cells grown on MDS atelocollagen compared with those grown on conventional atelocollagen. The association between ITG and FAK activation has been reported previously; for example, blocking ITG $\beta 1$ was shown to inhibit FAK phosphorylation in human lens epithelial cells (31), and FAK phosphorylation was found to be significantly decreased in ITG $\beta 1$ conditional knockout mice (32). Thus, MDS atelocollagen may reduce FAK activation via low ITG expression, thereby suppressing dedifferentiation and resistance to apoptosis. This hypothesis is supported by a previous study reporting that FAK suppression was observed in mouse primary hepatocytes and various cell lines cultured on soft collagen gel $(29,33)$. Time-course analysis using the stem cell marker Lgr5 as well as several ducts/progenitors, including Cd44, Prom1, Krt19 and Sox9, may shed more light on these findings (34). In addition, immunohistochemical analysis of CD44 and Sox9 may enable the characterization of the cell state (35).

The present study had certain limitations. We were unable to compare long-term cultures over the past week. Due to the 

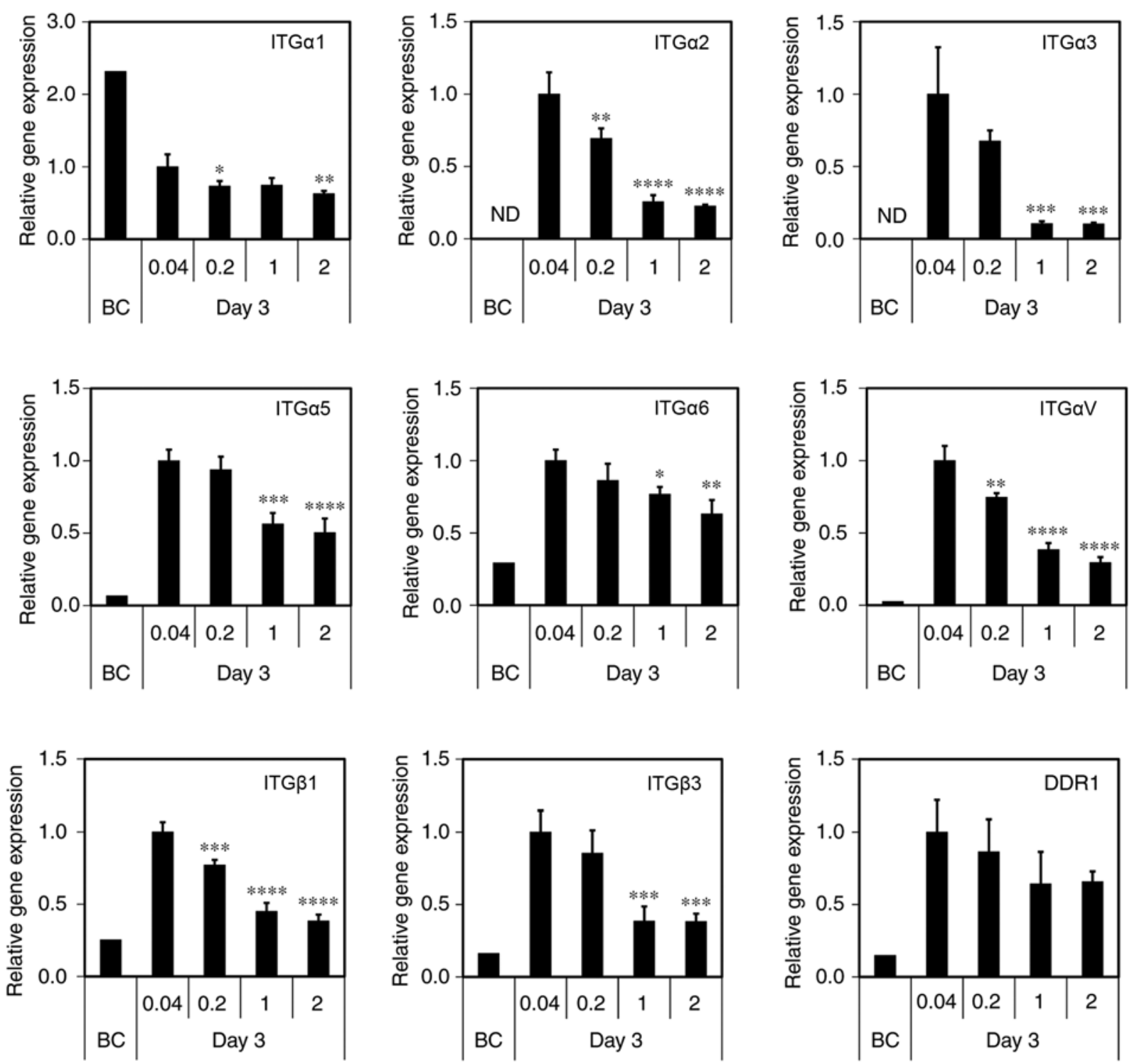

Figure 6. Integrin and discoidin domain receptor 1 gene expression. Quantitative RT-PCR analysis on day 3 of primary human hepatocyte (PHH) culture. Uncultured PHHs on day 0 [before culture (BC)]. The data are presented as relative gene expression normalized to that in cells grown on conventional $0.04 \mathrm{mg} / \mathrm{cm}^{2}$ atelocollagen. BC: $\mathrm{N}=1$. Day 3: $\mathrm{N}=4$. Statistical analysis was performed using one-way analysis of variance followed by Tukey's post hoc test. The post hoc test was performed for comparison with $0.04 \mathrm{mg} / \mathrm{cm}^{2} .{ }^{*} \mathrm{P}<0.05,{ }^{* *} \mathrm{P}<0.01,{ }^{* * * *} \mathrm{P}<0.001,{ }^{* * * * *} \mathrm{P}<0.0001$, ND, not detected; ITG, integrin; DDR, discoidin domain receptor.

culture on the conventional collagen coat to be compared, the enzymatic activity is abruptly lowered, rendering the use of the assay within 3 days difficult. Although useful methods for long-term culture, such as sandwich culture method, have previously been reported (28), the culture conditions are significantly different. It is essential to devise methods to ensure that similar conditions are maintained in the comparative control groups. The staining with annexin $\mathrm{V}$ may be effective in the evaluation of cell death in the culture. Annexin V has been recognized as a useful sensitive probe for detecting phosphatidylserine exposure on the cell membrane. The detection of annexin $\mathrm{V}$ bound to the cell surface indicates the initial stage of apoptosis. Therefore, it is also useful for distinguishing the two types of cell death, apoptosis and necrosis. We intend to use MDS atelocollagen in different cell culture methods, including sandwich culture and 3D cell culture. To achieve this, we need to change the culture protocol and the detection assay.
In various long-term culture methods, wherein the number of cells suitable for each condition, the composition of the culture medium, and the exchange timing of the culture medium, as well as the exchange method employed are different, it is crucial to identify the best aligned conditions to facilitate the evaluation.

In conclusion, our results indicate that the structure of atelocollagen scaffolds may be altered by the atelocollagen content, thereby leading to changes in the function and morphology of PHHs. Furthermore, MDS atelocollagen is more useful compared with conventional atelocollagen for enhancing hepatic function. Optimization of the ECM and the presence of non-parenchymal cells or other factors may be required for obtaining completely functional PHHs in vitro. We believe that co-culture and/or sandwich culture may further improve the maintenance of hepatic cell function; however, this may lead to the formation of a complex 
model. MDS atelocollagen provides a simple culture model with similar utility as conventional atelocollagen-coated cultures; furthermore, MDS atelocollagen provides a clear superiority for maintaining PHHs in culture. Therefore, MDS atelocollagen may be used as an alternative scaffold for $\mathrm{PHH}$ culture for drug development procedures, particularly for the evaluation of human hepatic drug metabolism, drug clearance, drug-drug interactions, transporter activity and hepatotoxicity.

\section{Acknowledgements}

The authors would like to thank Toshihiro Nagai (Keio University) for his assistance with SEM and TEM and Professor Shoen Kume (Tokyo Institute of Technology) for the helpful discussion.

\section{Funding}

The present study did not receive any specific grant from funding agencies in the public, commercial, or not-for-profit sectors.

\section{Availability of data and materials}

The datasets used and/or analyzed during the present study are available from the corresponding author on reasonable request.

\section{Authors' contributions}

TS conceived the project, performed research, analyzed the data, and was a major contributor to the preparation of the manuscript. KS and IF supervised the study. IF contributed to the preparation of the manuscripts. All authors have read and approved the final version of the manuscript.

\section{Ethics approval and consent to participate}

Not applicable.

\section{Patient consent for publication}

Not applicable.

\section{Competing interests}

The authors declare that they have no competing interests.

\section{References}

1. Godoy P, Hewitt NJ, Albrecht U, Andersen ME, Ansari A, Bhattacharya S, Bode JG, Bolleyn J, Borner C, Böttger J, et al: Recent advances in 2D and 3D in vitro systems using primary hepatocytes, alternative hepatocyte sources and non-parenchymal liver cells and their use in investigating mechanisms of hepatotoxicity, cell signaling and ADME. Arch Toxicol 87: 1315-1530, 2013.

2. Zeilinger K, Freyer N, Damm G, Seehofer D and Knöspel F: Cell sources for in vitro human liver cell culture models. Exp Biol Med (Maywood) 241: 1684-1698, 2016.

3. Fraczek J, Bolleyn J, Vanhaecke T, Rogiers V and Vinken M: Primary hepatocyte cultures for pharmaco-toxicological studies: At the busy crossroad of various anti-dedifferentiation strategies. Arch Toxicol 87: 577-610, 2013.
4. Lee SY, Kim HJ and Choi D: Cell sources, liver support systems and liver tissue engineering: Alternatives to liver transplantation. Int J Stem Cells 8: 36-47, 2015.

5. Beigel J, Fella K, Kramer PJ, Kroeger M and Hewitt P: Genomics and proteomics analysis of cultured primary rat hepatocytes. Toxicol In Vitro 22: 171-181, 2008

6. Godoy P, Schmidt-Heck W, Natarajan K, Lucendo-Villarin B, Szkolnicka D, Asplund A, Björquist P, Widera A, Stöber R, Campos G, et al: Gene networks and transcription factor motifs defining the differentiation of stem cells into hepatocyte-like cells. J Hepatol 63: 934-942, 2015.

7. Baxter M, Withey S, Harrison S, Segeritz CP, Zhang F, Atkinson-Dell R, Rowe C, Gerrard DT, Sison-Young R, Jenkins R, et al: Phenotypic and functional analyses show stem cell-derived hepatocyte-like cells better mimic fetal rather than adult hepatocytes. J Hepatol 62: 581-589, 2015.

8. Tuschl G, Hrach J, Walter Y, Hewitt PG and Mueller SO: Serum-free collagen sandwich cultures of adult rat hepatocytes maintain liver-like properties long term: A valuable model for in vitro toxicity and drug-drug interaction studies. Chem Biol Interact 181: 124-137, 2009.

9. Rowe C, Goldring CEP, Kitteringham NR, Jenkins RE, Lane BS, Sanderson C, Elliott V, Platt V, Metcalfe P and Park BK: Network analysis of primary hepatocyte dedifferentiation using a shotgun proteomics approach research articles. J Proteome Res 9: 2658-2668, 2010

10. Baker TK, Carfagna MA, Gao H, Dow ER, Li Q, Searfoss GH and Ryan TP: Temporal gene expression analysis of monolayer cultured rat hepatocytes. Chem Res Toxicol 14: 1218-1231, 2001.

11. Bhatia SN, Balis UJ, Yarmush ML and Toner M: Effect of cell-cell interactions in preservation of cellular phenotype: Cocultivation of hepatocytes and nonparenchymal cells. FASEB J 13: 1883-1900, 1999.

12. Skett P: Problems in using isolated and cultured hepatocytes for xenobiotic metabolism/metabolism-based toxicity testing-Solutions. Toxicol In Vitro 8: 491-504, 1994.

13. Skett $\mathrm{P}$ and Bayliss M: Time for a consistent approach to preparing and culturing hepatocytes. Xenobiotica 26: 1-7, 1996.

14. Choi HJ and Choi D: Successful mouse hepatocyte culture with sandwich collagen gel formation. J Korean Surg Soc 84: 202-208, 2013.

15. Dunn JCY, Tompkins RG and Yarmush ML: Hepatocytes in collagen sandwich: Evidence for transcriptional and translational regulation. J Cell Biol 116: 1043-1053, 1992.

16. Yoshida J, Oshikata-Miyazaki A, Yokoo S, Yamagami S, Takezawa T and Amano S: Development and evaluation of porcine atelocollagen vitrigel membrane with a spherical curve and transplantable artificial corneal endothelial grafts. Investig Ophthalmol Vis Sci 55: 4975-4981, 2014.

17. Kim BS, Yang SS and Lee J: Precoating of biphasic calcium phosphate bone substitute with atelocollagen enhances bone regeneration through stimulation of osteoclast activation and angiogenesis. J Biomed Mater Res A 105: 1446-1456, 2017.

18. Sano A, Maeda M, Nagahara S, Ochiya T, Honma K, Itoh H, Miyata $\mathrm{T}$ and Fujioka K: Atelocollagen for protein and gene delivery. Adv Drug Deliv Rev 55: 1651-1677, 2003.

19. Fujimoto I and Takei Y: Atelocollagen-mediated siRNA delivery: Future promise for therapeutic application. Ther Deliv 5: 369-371, 2014.

20. Takezawa T, Takeuchi T, Nitani A, Takayama Y, Kino-oka M, Taya $\mathrm{M}$ and Enosawa S: Collagen vitrigel membrane useful for paracrine assays in vitro and drug delivery systems in vivo. J Biotechnol 131: 76-83, 2007.

21. Calderón-Colón X, Xia Z, Breidenich JL, Mulreany DG, Guo Q, Uy OM, Tiffany JE, Freund DE, McCally RL, Schein OD, et al: Structure and properties of collagen vitrigel membranes for ocular repair and regeneration applications. Biomaterials 33: 8286-8295, 2012.

22. Wolf A: The Jordan watershed: Past attempts at cooperation and lessons for the future. Water Int 18: 5-17, 1993.

23. Blateyron F: The areal feature parameters. In: Characterisation of Areal Surface Texture. Leach R (ed). Springer Berlin Heidelberg, Berlin, Heidelberg, pp45-65, 2013.

24. Czekaj P: Phenobarbital-induced expression of cytochrome P450 genes. Acta Biochim Pol 47: 1093-1105, 2000.

25. Livak KJ and Schmittgen TD: Analysis of relative gene expression data using real-time quantitative PCR and the 2(-Delta Delta C(T)) method. Methods 25: 402-408, 2001.

26. Yamauchi M and Sricholpech M: Lysine post-translational modifications of collagen. Essays Biochem 52: 113-133, 2012. 
27. Zelts $\mathrm{C}$ and Gulberg D: The integrin-collagen connection-a glue for tissue repair? J Cell Sci 129: 653-664, 2016.

28. Burkhardt B, Martinez-Sanchez JJ, Bachmann A, Ladurner R and Nüssler AK: Long-term culture of primary hepatocytes: New matrices and microfluidic devices. Hepatol Int 8: 14-22, 2014.

29. Desai SS, Tung JC, Zhou VX, Grenert JP, Malato Y, Rezvani M, Español-Suñer R, Willenbring H, Weaver VM and Chang TT: Physiological ranges of matrix rigidity modulate primary mouse hepatocyte function in part through hepatocyte nuclear factor 4 alpha. Hepatology 64: 261-275, 2016.

30. Godoy P, Hengstler JG, Ilkavets I, Meyer C, Bachmann A, Muller A, Tuschl G, Mueller SO and Dooley S: Extracellular matrix modulates sensitivity of hepatocytes to fibroblastoid dedifferentiation and transforming growth factor $\beta$-induced apoptosis. Hepatology 49: 2031-2043, 2009.

31. Liu J, Yan XL, Zheng XL, Mei L, Wang S, Han J and Yan H: Electric field exposure promotes epithelial-mesenchymal transition in human lens epithelial cells via integrin $\beta 1$-FAK signaling. Mol Med Rep 16: 4008-4014, 2017.

32. Wang Y, Terrell AM, Riggio BA, Anand D, Lachke SA and Duncan MK: $\beta 1$-integrin deletion from the lens activates cellular stress responses leading to apoptosis and fibrosis. Investig Ophthalmol Vis Sci 58: 3896-3922, 2017.
33. Wang YK, Wang YH, Wang CZ, Sung JM, Chiu WT, Lin SH, Chang YH and Tang MJ: Rigidity of collagen fibrils controls collagen gel-induced down-regulation of focal adhesion complex proteins mediated by alpha2beta1 integrin. J Biol Chem 278: 21886-21892, 2003.

34. Kuijk EW, Rasmussen S, Blokzijl F, Huch M, Gehart H, Toonen P, Begthel H, Clevers H, Geurts AM and Cuppen E: Generation and characterization of rat liver stem cell lines and their engraftment in a rat model of liver failure. Sci Rep 6: 22154, 2016.

35. Wang S, Lee Y, Kim J, Hyun J, Lee K, Kim Y and Jung Y: Potential role of Hedgehog pathway in liver response to radiation. PLoS One 8: e74141, 2013.

This work is licensed under a Creative Commons Attribution-NonCommercial-NoDerivatives 4.0 International (CC BY-NC-ND 4.0) License. 